\title{
PENGEMBANGAN PERANGKAT LUNAK PARAMETER PROSES MBE-P3TM
}

\author{
Prajitno \\ Pusat Penelitian dan Pengembangan Teknologi Maju
}

\begin{abstract}
ABSTRAK
PENGEMBANGAN PERANGKAT LUNAK PARAMETER PROSES MBE-P3TM. Telah dilakukan analisis, perancangan dan pembuatan program komputer untuk mendukung Sistem Instrumentasi dan Kendali MBE di P3TM. Komputer untuk Instrumentasi MBE dilengkapi dengan kartu PCL-745B komunikasi serial untuk jaringan RS485. Komputer berfungsi untuk melakukan akuisisi data parameter proses MBE dan menampilkan data dalam bentuk numerik maupun diagram batang dan visualisasi posisi trafo variac filamen sumber elektron dan trafo variac sumber tegangan tinggi osilator daya. Kartu antarmuka Advantech PCL-718 dipasang di salah satu slot komputer bantu, berfungsi untuk mengubah masukan sinyal analog yang telah dikondisikan sesuai persyaratan menjadi bentuk dijital. Data dalam bentuk dijital dikirimkan ke komputer utama secara serial lewat pasangan kabel terpilin dengan protokol RS-485. Program komputer yang dikembangkan telah diuji coba di laboratorium secara simulasi dan juga diuji coba langsung pada saat MBE dioperasikan, memberikan hasil unjuk kerja tampilan yang stabil pada layar monitor. Hasil percobaan menunjukkan bahwa tampilan program komputer dapat memberi tambahan informasi bagi operator saat mengoperasikan MBE.
\end{abstract}

\begin{abstract}
DEVELOPMENT OF SOFTWARE FOR PROCESS PARAMETERS OF THE EBM-P3TM. Analysis, design and making of computer program to support the instrumentation and control of EBM in P3TM have been done. Computer for the Instrumentation of EBM provided with a PCL-745B card serial communications for the network of RS485. The function of computer is to perform the data acquisition of process parameters of EBM and display data in the form of numeral and bar graph and also visualizing the position of variac transformer filament of electron source and variac transformer of high voltage supply for power oscillator. The Advantech PCL-718 interface card is attached in one of the slave computer slot, functioning to convert analog signal input which have been conditioned to become digital form. Data in the form of digital is delivered to master computer serially pass the twisted pair cable with the RS-485 protocol. Computer program which was developed have been tested in laboratory with simulation and also have been tested direct on the operation of MBE, giving result of stable appearance performance at screen monitor. Result of experiment indicate that the appearance of computer program can give an additional information to the operator during the operation of EBM.
\end{abstract}

\section{PENDAHULUAN}

$S_{\mathrm{s}}^{\mathrm{e}}$ esuai dengan tugas pokok dan fungsi Pusat Penelitian dan Pengembangan Teknologi Maju (P3TM) yaitu melakukan penelitian dan pengembangan teknologi nuklir yang dapat menunjang pembangunan nasional, salah satunya P3TM ditugaskan untuk mengembangkan teknologi akselerator yaitu melakukan rekayasa Mesin Berkas Elektron.
Mesin Berkas Elektron (MBE) merupakan perangkat akselerator penghasil elektron. Pada prinsipnya MBE terdiri dari beberapa komponen utama yaitu sumber elektron, tabung pemercepat, generator tegangan tinggi (GTT), sistem pemfokus, sistem pemayar, sistem vakum dan sistem konveyor.

Untuk mendukung bekerjanya MBE yang dibuat di P3TM, telah dilakukan perancangan Sistem Instrumentasi dan

Prajitno, dkk. 
Kendali (SIK) yang dirancang berbasis komputer dan berstruktur terdistribusi serta atas dasar konsep Computer Integrated Manufacturing (CIM) yang bertujuan agar informasi proses dan manajemen tersedia pada saat dan tempat yang tepat, sehingga mendukung keputusan yang lebih baik di semua level ${ }^{[1]}$. Saat ini SIK yang dibuat menerapkan CIM dengan 3 level.

Level 1 merupakan process level terdiri dari embedded controllers untuk pengukuran dan pengendalian parameter proses.

Level 2 adalah supervision level berupa operation console untuk memantau dan mengendalikan proses melalui local controllers (process supervision).

Level 3 atau plant management level merupakan information pool dengan komunikasi data antara server dan client (operation console adalah salah satu client) melalui jaringan komputer.

Tujuan dari penelitian ini adalah untuk merealisasikan rancangan SIK MBE yang berhubungan dengan pengembangan perangkat lunak komputer, khususnya untuk akuisisi data dan menampilkan informasi proses.

Komputer berfungsi sebagai embedded controllers tugasnya mengontrol modul Advantech PCL-718B yang dipasang pada salah satu slot, digunakan untuk mengubah masukan sinyal analog parameter proses menjadi bentuk dijital. Sinyal analog yang berasal dari parameter proses adalah:

1. Trafo. filamen sumber elektron

2. Tegangan Generator Tegangan Tinggi (GTT)

3. Arus berkas

4. Arus GTT

5. Arus kolom

6. Trafo Catu daya GTT

7. Suhu ruang MBE

8. Tingkat kelembaban ruang $\mathrm{MBE}$

Proses untuk mengubah sinyal analog menjadi bentuk dijital dilakukan secara multipleks atau berurutan sesuai dengan urutan masukan sinyal analog. Hasil data dijital 8 masukan analog selanjutnya dikumpulkan dan dikirimkan ke komputer utama secara serial lewat protokol RS-485. Dalam melakukan tugasnya komputer menggunakan Sistem Operasi MS-DOS (Microsoft Disk Operating System) versi 6.22. Digunakannya sistem operasi MSDOS ini adalah dengan maksud setelah program yang dikembangkan selesai dan teruji, semuanya akan disimpan dalam Disk On Chip sehingga keandalan sistem diharapkan lebih baik karena tidak diperlukan media penyimpan yang mengggunakan bagian berputar (moving part).

Tampilan di layar monitor akan berubah-ubah sesuai dengan kondisi sinyal analog dalam proses MBE dan hal ini akan memberikan informasi kepada operator dalam mengoperasikan MBE sehingga mempermudah dan diharapkan dapat meringankan tugasnya.

\section{TATA KERJA}

\section{Akuisisi Data}

Gambar 1. adalah blok diagram sistem akuisisi data, masukan sinyal mentah adalah dalam bentuk tegangan analog dimana amplitudo secara kontinyu berubah terhadap waktu.

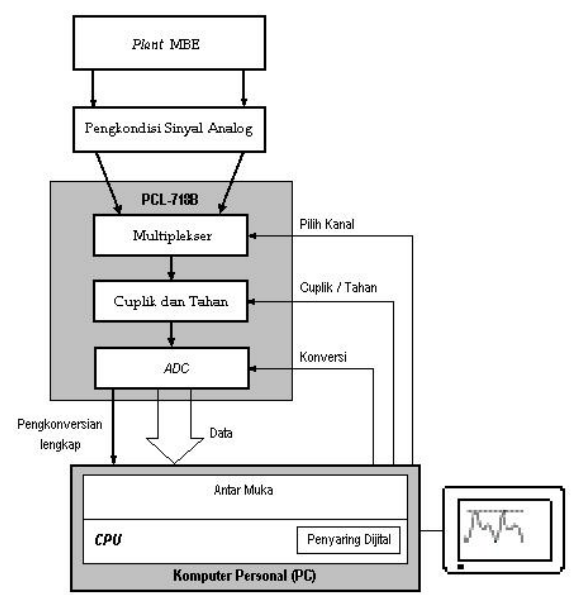

Gambar 1. Blok diagram sistem akuisisi data 
Perubahan tegangan ini dimonitor dan dikondisikan agar dapat disesuaikan dengan standar kebutuhan yang telah ditentukan. Pengkondisian sinyal biasanya melibatkan rangkaian elektronik untuk modifika-si sinyal dengan penguatan dan penyaringan. Setelah itu semua tegangan analog dicuplik secara bergantian dengan waktu jeda tetap.

Untuk PCL-718B frekuensi pencuplikan sudah ditentukan pabrik pembuatnya yaitu $^{[5]}$ :

$$
f_{\text {cuplik }}=\frac{2 \mathrm{MHz}}{\text { param [5] xparam [6] }}
$$

dan pengguna hanya diminta memasukkan nilai param[5] dan param[6]. Apabila param[5] $=5$ dan param[6] $=10$ maka $\mathrm{f}_{\text {cuplik }}=40 \mathrm{kHz}$.

Sinyal analog yang dicuplik kemudian dikonversi menjadi bentuk dijital dan data hasil konversi selanjutnya disimpan dalam memori komputer. Perangkat lunak komputer melakukan penyaringan secara dijital dan menampilkan data secara langsung di layar monitor. Penyaringan dijital menggunakan metode rata-rata ${ }^{[9]}$, dimana setiap cuplikan sinyal masukan analog dikonversi menjadi bentuk dijital sebanyak 20 kali dan data tersebut dirata-rata sehingga diperoleh satu data yang akan ditampilkan. Dalam bentuk persamaan matematis dapat dituliskan sebagai berikut:

$$
y[i]=\frac{1}{M} \sum_{j=0}^{M-1} x[i+j]
$$

dengan :

$$
\begin{array}{ll}
\mathrm{x}[i] & =\text { sinyal masukan } \\
\mathrm{y}[i+j] & =\text { sinyal keluaran } \\
\mathrm{M} & =\text { jumlah titik yang dirata-rata }
\end{array}
$$

\section{Pengembangan perangkat lunak}

Sekuensial linier adalah sebuah pendekatan sederhana untuk pengembangan perangkat lunak yang sistematik dan sekuensial yang dimulai pada tingkat dan kemajuan sistem pada seluruh analisis, disain, kode, pengujian dan pemeliharaan ${ }^{[8]}$.
Model sekuensial linier melingkupi kegiatan-kegiatan berikut (lihat Gambar 2):

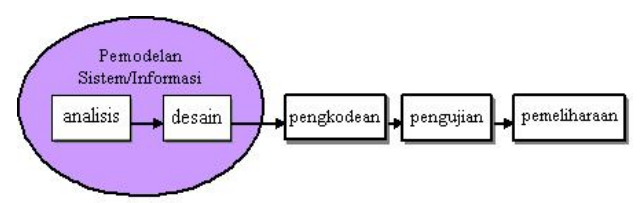

Gambar 2. Model sekuensial linier

- Rekayasa dan pemodelan sistem/ informasi. Karena perangkat lunak selalu merupakan bagian dari suatu sistem yang besar, kerja dimulai dengan menentukan syarat dari semua elemen sistem dan mengalokasikan beberapa subset dari kebutuhan ke perangkat lunak tersebut. Pandangan sistem ini penting ketika perangkat lunak harus berhubungan dengan elemen lain seperti perangkat keras, manusia dan basis data.

- Analisis kebutuhan perangkat lunak. Proses pengumpulan kebutuhan diintensifkan dan difokuskan, khususnya pada perangkat lunak. Untuk memahami sifat dasar dari program yang akan dibangun, analis perangkat lunak harus memahami domain informasi, sifat, unjuk kerja dan antarmuka yang diperlukan.

- Disain. Disain perangkat lunak sebenarnya adalah proses multi langkah yang terfokus pada empat atribut program berbeda: struktur data, arsitektur perangkat lunak, gambaran antarmuka dan detil prosedur (algoritma).

- Pembangkitan kode. Disain harus menterjemahkan data atau pemecahan masalah yang telah dirancang ke dalam bahasa pemrograman komputer yang telah ditentukan.

- Pengujian. Setelah program selesai dibuat, pengujian program dimulai. Proses pengujian difokuskan pada logika internal dari perangkat lunak, diyakinkan bahwa dengan memberi masukan yang telah diketahui akan menghasilkan keluaran sesuai yang diharapkan. 
- Pemeliharaan. Perangkat lunak yang telah selesai dikembangkan dapat mengalami perubahan atau penambahan sesuai dengan permintaan pengguna dan perkembangan kebutuhan.

\section{Diagram Aliran Data (Data Flow Diagram)}

Diagram Aliran Data (DAD) adalah teknik grafik yang digunakan untuk menggambarkan aliran informasi dan transformasi yang diaplikasikan pada saat data bergerak dari masukan menjadi keluaran. Diagram ini dapat juga digunakan untuk menggambarkan jaringan suatu sistem, dimana sistem dapat otomatis, manual atau gabungan keduanya. Pembuatan DAD dimulai dengan sumber informasi atau asal data dimana data selanjutnya diproses untuk dihasilkan data baru atau disimpan dalam bentuk file data.

DAD juga dapat digunakan untuk menggambarkan sistem atau perangkat lunak pada setiap tingkat dan dapat dipecah-pecah. Level 0 pada DAD (Gambar 3) disebut model sistem fundamental atau model konteks, menggambarkan keseluruhan elemen perangkat lunak sebagai satu lingkaran dengan masukan dan keluaran data dinyatakan oleh panah masuk dan keluar. Proses lanjutan (lingkaran) dan aliran informasi yang digambarkan sebagai DAD level 0 dibagi-bagi untuk diungkapkan lebih detil pada level yang lebih tinggi (Gambar 4).

Aplikasi perangkat lunak untuk Sistem Instrumentasi dan Kendali MBE merupakan time dependent (tergantung pada waktu) atau lebih banyak informasi control-oriented data. Dimana sistem waktu nyata (real time) harus berinteraksi dengan dunia nyata di dalam kerangka waktu yang ditentukan oleh dunia nyata.

Simbol-simbol yang digunakan meng-gambarkan DAD untuk analisis perangkat lunak waktu nyata adalah: simbol kotak digunakan untuk menggambarkan eksternal entity, yaitu elemen sistem misalnya perangkat keras, manusia, program lain atau sistem lain yang menghasilkan informasi untuk diubah oleh perangkat lunak atau menerima informasi dihasilkan oleh perangkat lunak. Lingkaran merepresentasikan sebuah proses atau transformasi yang diaplikasikan ke data atau kontrol dan mengubahnya dengan berbagai macam cara.

Keseluruhan pendekatan proses abstraksi untuk perancangan yang berorientasi ke aliran data digambarkan seperti pada Gambar 7. (Lampiran 1).

\section{MODEL KONTEKS SIK MBE}

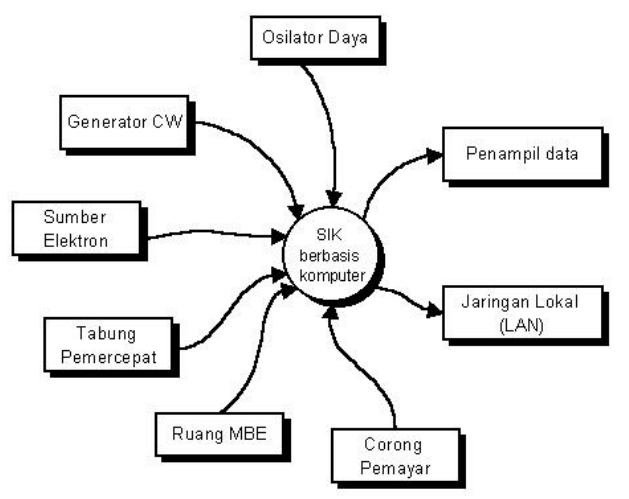

Gambar 3. Diagram model konteks SIK MBE berbasis komputer

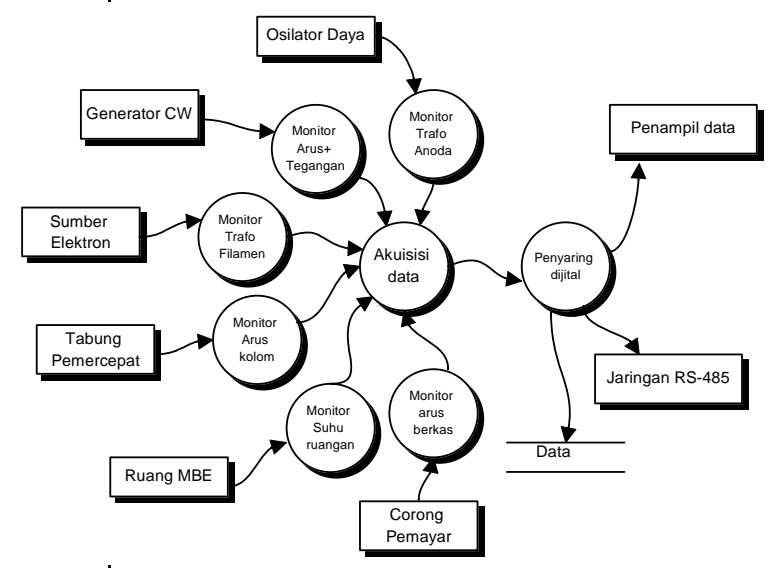

Gambar 4. DAD-1 sistem akuisisi data 


\section{HASIL DAN PEMBAHASAN}

Hasil yang diperoleh dari pengembangan perangkat lunak untuk mendukung bekerjanya MBE-P3TM adalah tampilan parameter proses seperti Gambar 5, dimana masukan sinyal analog setelah dikonversi menjadi data dijital dan disaring secara dijital ditampilkan dalam bentuk numerik dan diagram batang.

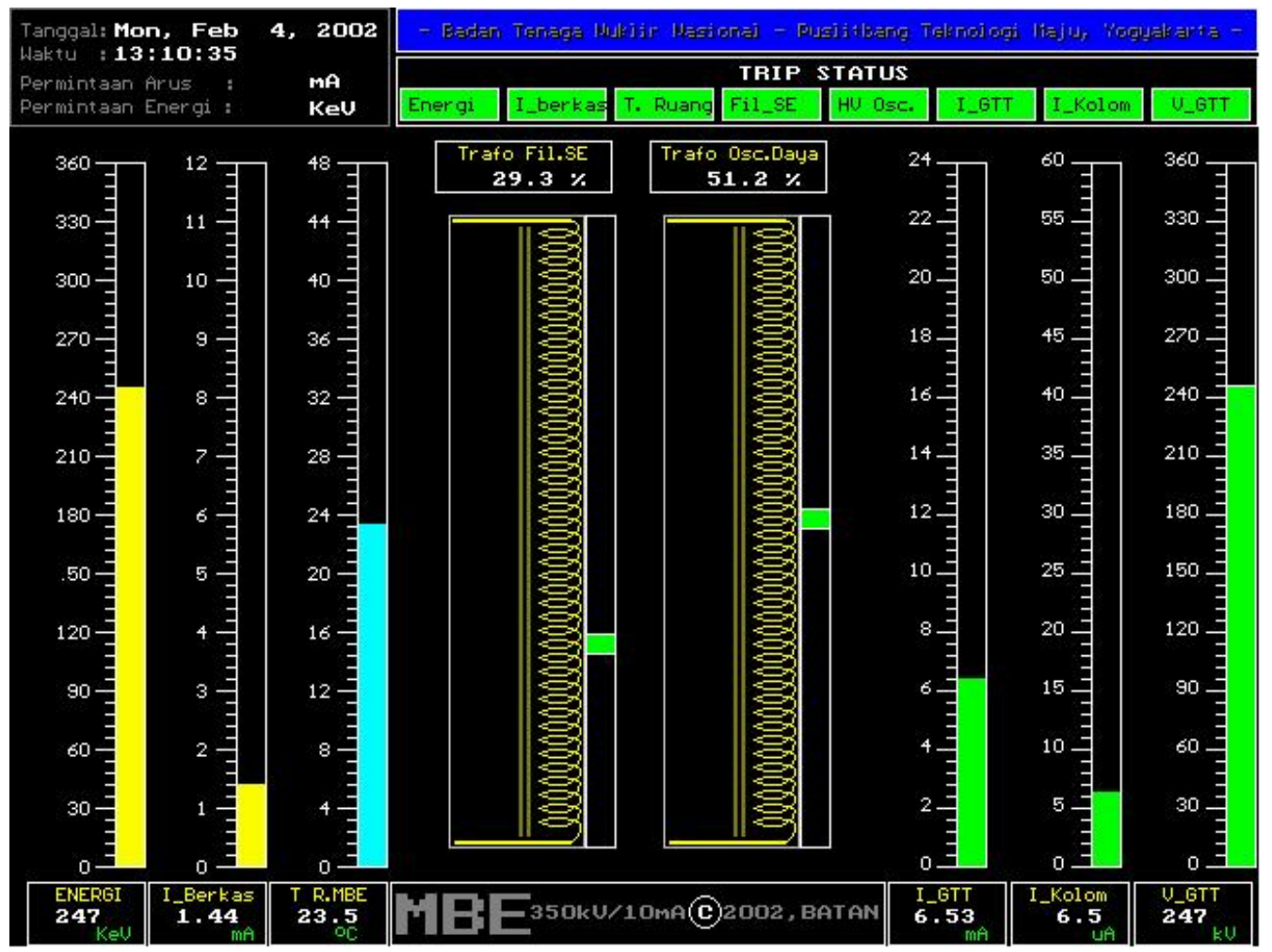

Gambar 5. Tampilan layar monitor komputer bantu

Pada bagian tengah tampilan layar monitor komputer menggambarkan posisi prosentase trafo filamen sumber elektron dan trafo osilator daya yang digunakan untuk mencatu anoda tabung osilator daya. Kedua trafo ini adalah jenis variac yang digambarkan dengan kontak geser yang menempel pada lilitan kawat trafo. Tanda 1 dan 2 adalah menunjukkan posisi kontak geser, saat percobaan secara simulasi dilakukan diatur trafo filamen pada posisi 29,3\% dan Trafo Tegangan Tinggi Osilator daya pada posisi 51,2\%. Pada bagian kiri tampilan ada 3 bar graph dan data numerik yaitu energi $247 \mathrm{KeV}$, Arus berkas 1,44 mA dan suhu ruang $\mathrm{MBE} 23,5^{\circ} \mathrm{C}$, sedangkan pada bagian kanan tampilan juga tertampil 3 bar graph dan data numerik untuk menggambarkan Arus GTT 6,53 mA, arus kolom 6,5 $\mu \mathrm{A}$ dan tegangan GTT $\mathrm{kV}$.

Kalibrasi tampilan layar monitor dilakukan dengan memban-dingkan sinyal analog yang diukur menggunakan Digital Multi Meter (DMM). Untuk menyamakan data yang akan ditampilkan di layar monitor dengan hasil pengukuran DMM, data sesuai dengan hasil pengukuran. 
dikalikan dengan suatu konstanta sesuai hasil perhitungan.

Data hasil akuisisi juga disimpan dalam berkas (file) dengan format ASCII, sepeti pada Gambar 6.

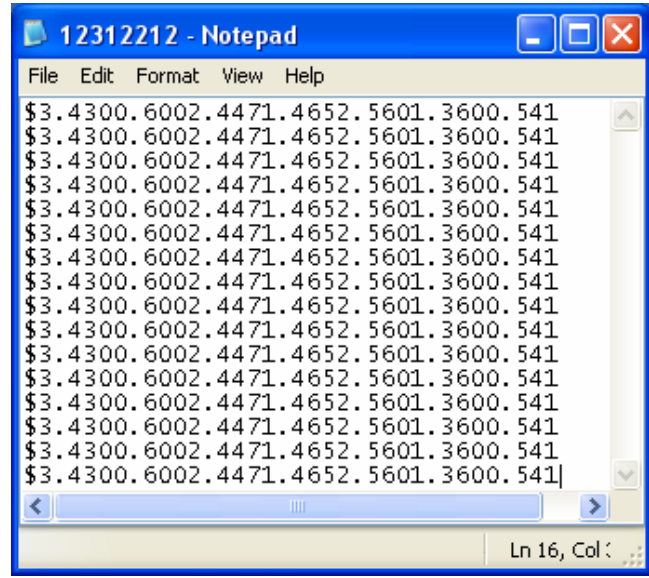

Gambar 6. Contoh berkas hasil akuisisi

\section{KESIMPULAN}

Dari hasil pengamatan pada saat MBE dioperasikan parameter proses dapat tertampil dengan baik dan gambaran kontak geser dapat mengikuti perubahan tegangan pada saat operator menaikkan atau menurunkan tegangan tinggi pemercepat elektron dan tegangan untuk catu filamen sumber elektron. Dengan demikian dapat disimpulkan bahwa perangkat lunak untuk akuisisi parameter proses MBE yang ditampilkan dalam bentuk numerik maupun diagram batang dapat memberikan informasi dan kemudahan kepada operator saat mengoperasikan MBE .

\section{DAFTAR PUSTAKA}

1. RANCANGAN DASAR INSTRUMENTASI DAN KENDALI MESIN BERKAS ELEKTRON, Dokumen Proyek Rancang Bangun MBE No. RD1/05/97, Rev.0, 1997
2. PCL-718 High Performance Data Acquisition Card, PC-Lab Card User's Manual (1993)

3. PCL-743/745B, Advantech Dual Post RS-422/485, User's Manual (1994)

4. www.bb-elec.com, RS-422 and RS-485 Application Note , October (1997).

5. Kumpulan Makalah Semi-Nar Sehari Perancangan MBE 500 Kev/10mA, PPNY-BATAN, Yogyakarta, 16 Januari (1996).

6. S.PRESSMAN, ROGER S, Software Engineering A Practitioner's Approach, McGraw Hill Book Company, (1997).

7. STEVEN W. SMITH, Digital Signal Processing, California Technical Publishing, (1999).

\section{LAMPIRAN}

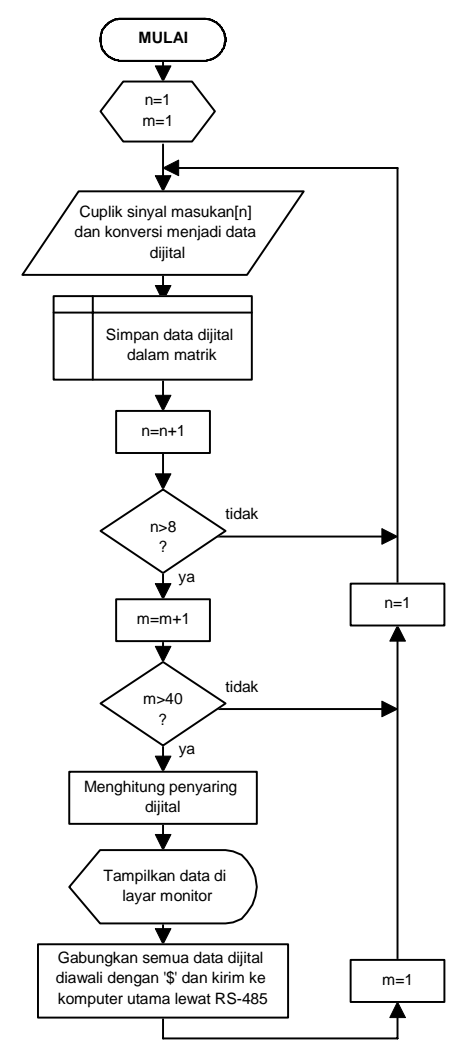

Gambar 7. Diagram alir perangkat lunak parameter proses MBE 